ISSN: 0212-5374

DOI: http://dx.doi.org/10.14201/et2015331143161

\title{
JUEGO, TEATRO Y EDUCACIÓN INFANTIL. LA OBRA TEATRAL KUBIK Y SU VALOR PEDAGÓGICO- ARTÍSTICO
}

\author{
Play, theatre and early childhood education. The theatre \\ play Kubik and its pedagogical-artistic value
}

\section{Jeu, théâtre et éducation. Le jouer Kubik et son valeur pédagogique-artistique}

\author{
Amaia Álvarez-Uria*, Alaitz Tresserras**, Edu Zelaieta**** y María Teresa \\ VIZCARRA***** $^{* * 2}$ \\ Euskal Herriko Unibertsitatea/Universidad del País Vasco (EHU/UPV). \\ Correo-e:*amaia.au@ebu.es; **alaitz.tresserras@ebu.es; ****edu.zelaieta@ebu.es; \\ ****:mariate.bizkarra@ebu.es
}

Recibido: 24-11-2013; Aceptado: 03-06-2014; Publicado: 30-04-2015

BIBLID [0212-5374 (2015) 33, 1; 143-161]

Ref. Bibl. AMAIA ÁLVAREZ-URIA, ALAITZ TRESSERRAS, EDU ZELAIETA y MARÍA TERESA VIZCARRA. Juego, teatro y educación infantil. La obra teatral Kubik y su valor pedagógico-artístico. Enseñanza \& Teaching, 33, 1-2015, 143-161.

RESUMEN: Este artículo analiza tres aspectos de la obra teatral de la compañía Teatro Paraíso Kubik: la efectividad comunicativa, el cuidado del espacio y la utilización de los recursos escénicos. Y lo hace teniendo en cuenta la adecuación de esta obra a un público infantil (1-3 años) al que históricamente no se le ha prestado mucha atención desde el teatro. Se analiza cómo se han acondicionado las estrategias de aprendizaje que se basan en la acción y el placer, es decir, en el juego, pilar tanto del aprendizaje infantil como del arte dramático, medio predominante en estas edades, y pilar tanto del aprendizaje infantil, como del arte dramático. Kubik es un 

JUEGO, TEATRO Y EDUCACIÓN INFANTIL...

recurso novedoso y atractivo para la comunidad educativa por lo dicho y porque facilita la educación integral de la primera infancia. La investigación está diseñada desde una perspectiva cualitativa, teniendo en cuenta las voces recogidas en la sesión formativa previa con las docentes, las notas de campo de diferentes representaciones teatrales y la valoración posterior del público adulto, todo ello plasmado en un sistema categorial utilizando el programa NVivo8. Esta investigación se centra en describir y evaluar desde un punto de vista pedagógico la contextualización de la obra, las herramientas escénicas utilizadas y la interacción entre juego y movimiento. Por todo esto Kubik es una buena herramienta didáctica, además de ser un medio adecuado para la iniciación en la educación artística, porque logra la identificación y cercanía con los niños y las niñas, y la conexión con su fase de desarrollo mediada por la exploración, la manipulación de objetos y el placer de la acción.

Palabras clave: Kubik; teatro infantil; juego simbólico; juego dramático; educación infantil.

SUMMARY: This article analyzes Kubik, a theatre play for children 1 to 3 yearold, conducted by the theatre company Teatro Paraíso: it's appropriate communicatively, they prepare very thorough fully the space, and the scenic tools are suitable for the children. And they do it taking in to account the adequacy of the play for an infant public (1-3 year-old) which historically hasn't been considered in theatre, and the fact that this theatrical play is based on action and pleasure, in other words, on the play, meaning playful action, predominant in children's life as well as the base for children learning and dramatic arts. These reasons reinforce the idea that Kubik is a novel and attractive resource for the educational community, and also, it facilitates the integral education to children of this age. The research is designed from a qualitative point of view, with the collected voices of the teachers in the formative sessions, the field notes from diverse representations and the later evaluation of the adult public, all of this captured in a categorical system provided by the NVivo8 program. It focuses on describing and evaluating, from a pedagogical point of view, the contextualization of the play, the pedagogical tools used, and the interaction between play and movement. Therefore, Kubik is a good pedagogical tool, and an adequate way to initiate children in the artistic education, because allows the identification and the nearness with children and the connection with their development phase, which uses the exploration, the object manipulation and the pleasure for action.

Key words: Kubik; children's theatre; symbolic play; creative drama; early childhood education.

RÉSUMÉ: Cet article présente le travail de la compagnie de théâtre Paraíso en tant que sont adéquation communicatif, il soins l'espace, et la utilisation de les moyens scénographiques. Et il tient compte de deux facteurs: l'adaptation à un public d'enfants (1-3 ans), traditionnellement plutôt négligé par l'art dramatique, et le fait que ce travail soit basé sur l'action et le plaisir, voire sur le jeu proprement dit, qui est à ce stade vital mais tout aussi, le support de l'apprentissage chez les jeunes enfants 

JUEGO, TEATRO Y EDUCACIÓN INFANTIL...

et d'une formation en art dramatique. Ces pour toutes ces raisons que Kubik peut être considéré un instrument nouveau et attrayant pour la communauté éducative et aussi, parce qu'il facilite l'éducation intégrale de la petite enfance. Cette investigation a été conçue d'un point de vue qualitatif, en prenant compte des opinions recueillies dans la session de formation préalable des enseignants, des notes prises lors des différentes représentations et de l'évaluation ultérieure du public adulte, tout étant incorporé dans un système catégoriel en utilisant le programme NVivo8; elle a pour objet principal la description et l'évaluation d'un pont de vue pédagogique des points suivants: la mise en contexte de la pièce, les outils pédagogiques utilisés et l'interaction entre jeu et mouvement. En somme, Kubik constitue un bon outil d'enseignement, un moyen adéquat pour l'initiation à l'éducation artistique, parce qu'il favorise aussi les processus d'identification des enfants, de proximité, et avec leur étape de développement induits par l'exploration, la manipulation d'objets et le plaisir de l'action.

Mots clés: Kubik; théâtre pour enfants; jeu symbolique; jeu dramatique; l'éducation des enfants.

\section{INTRODUCCIÓN}

El espectáculo Kubik es una coproducción de Teatro Paraíso y Teatro de La Guimbarde (Bélgica), realizado dentro del proyecto europeo Small Size Big Citizens. La compañía define la obra como: "En el espacio de juego, dos actores proyectan colores, formas y volúmenes, para dibujar un universo sensorial sobre el blanco original. Juntos descubren el placer de crear y mirar las imágenes mientras invitan a los pequeños espectadores a viajar, jugar, descubrir, imaginar y soñar. Un juego de construcciones que se transforma en un bosque de emociones".

En la investigación realizada por el grupo de investigación HEZIKERT de la Escuela Universitaria de Magisterio de Vitoria-Gasteiz se ha evaluado dicha obra teniendo en cuenta que está dirigida a un público de entre 1 y 3 años, circunstancia en sí valiosa por la escasa oferta teatral para este público. Gracias a la conexión existente entre el drama y el juego, esta obra tiene un gran valor pedagógico para esta etapa concreta del desarrollo infantil, por lo que nos parece una propuesta muy recomendable para la consecución de una educación holística y artística.

En este artículo se postula la obra teatral de la Compañía Teatro Paraíso Kubik dirigida a un público de entre 1 y 3 años, como una propuesta pedagógica innovadora. La investigación se basa en los datos recogidos por un equipo interdisciplinar de expertos de la Universidad del País Vasco/Euskal Herriko Unibertsitatea (UPV/ EHU) mediante métodos cualitativos y analiza: a) el valor pedagógico de la obra desde el punto de vista de la comunicación; b) la preparación de la escenografía; y c) la interacción entre el juego, los objetos y el movimiento.

Se deduce que la aportación pedagógica de la Compañía de Teatro Paraíso a la Educación Infantil (con la representación de la obra Kubik en este caso) se concreta en dos postulados: por un lado, la propuesta del arte dramático como 
metodología privilegiada para la consecución de una educación artística; y, por otro, el diseño de herramientas cercanas y coherentes en pro de una educación integral y global de la primera etapa infantil por medio de las artes escénicas. Se podría decir en palabras de una de las escasas autoras que reivindican la importancia de vivir la experiencia teatral como aprendizaje vital, cognitivo y artístico y que propone integrar el arte dramático en la enseñanza y en el aprendizaje en general y en el infantil en particular que Kubik es juego, tanto simbólico como dramático, y se inspira en el "arte-ciencia de lo vivido" (Gisèle Barret, 1991: 203).

Considerando que las investigaciones interesadas en el teatro para niños y niñas, especialmente en el teatro para menores de 3 años, todavía son muy escasas (Young y Powers, 2008), el arte en general y el arte dramático en particular se presentan en esta investigación como objeto de estudio pedagógico innovador y como oportunidad concretados en la obra Kubik, en tanto que favorece la citada educación integral y global atendiendo al crecimiento intelectual, sensorial y corporal de las niñas y los niños en los planos personal y social y a su vez posibilita la contextualización de la escuela en la sociedad. Si además se le añade la utilización educativa del juego en esta obra el valor pedagógico se multiplica. De esta manera, el juego se presenta como una actividad inmejorable para aprender y progresar en el desarrollo de las capacidades infantiles dando la oportunidad al niño y a la niña de interpretar la realidad reproduciendo escenas cotidianas y de adquirir nuevas experiencias y conocimientos de una forma natural.

Para Bruner el teatro es un poderoso medio para la exploración y el aprendizaje creativo (en Cutillas, 2006). Respecto al papel pedagógico del juego se puede afirmar que ayuda en el proceso de madurez infantil además de ser la actividad corporal natural más importante de la vida infantil. También se puede subrayar la labor socializadora del juego, pues, como sostiene Huizinga en su Homo Ludens (1972), el juego es "como un núcleo primario de la actividad humana" en la vida social (Cutillas, 2006: 589). Huizinga muestra la relación ente el juego y el teatro cuando dice que "sólo el drama por el hecho de conservar idéntica su cualidad de ser una acción, mantiene una conexión firme con el juego" (Cutillas, 2006: 602-603).

Mediante los diferentes tipos de representación se concibe el desarrollo intelectual: "La representación inactiva, la representación icónica y la representación simbólica: conocer algo por medio de la acción, a través de un dibujo o una imagen y mediante formas simbólicas como el lenguaje" (tomado de Bruner en Cutillas, 2006: 594). Y estos son, precisamente, los tres tipos de representación que se pueden encontrar en Kubik como se verá más adelante.

El juego es «Un invernadero en el que poder combinar pensamiento, lenguaje y fantasía" (Cutillas, 2006: 594), por lo que las competencias cognitivas, comunicativas y creativo-imaginativas se ven nutridas con la dramatización y el teatro entendidos como juego en general, y con la obra Kubik en particular. 
La pedagogía del juego dramático se hace visible a través de la acción descrita por Barret (1991), una de las principales autoras que intentan acercar el juego y el arte dramático al aula basándose en tres nociones:

- Lo lúdico o la pedagogía del juego que concuerda perfectamente con la definición y los objetivos de la expresión dramática. "Tanto el juego como el arte dramático se basan en la acción (y la reacción), y si a la acción le aportamos el placer (de la vida) al ejercitarla, el aprendizaje está garantizado" (Barret, 1991: 70).

- $\quad$ El proceso que es consecuencia directa de lo anterior es mucho más significativo que el producto final. Lo verdaderamente importante es la actividad, el proceso de la función lúdica, la exploración y la manipulación para descubrirse a sí mismo, a los demás y al mundo circundante. La persona que juega y su disfrute son las claves del juego, del proceso lúdico, que existen mientras dura este (Barret, 1991).

- La polisemia que se refiere a la multiplicidad de sentidos y significados que tiene cada signo y que no se deben reducir a uno puesto que cada participante vivirá la experiencia lúdico-artística a su manera y hará su propio camino personal y colectivo (Barret, 1991). El artista-pedagogo tendrá que estar atento a las diferentes manifestaciones e interacciones que sucedan en el aula y ayudar a que se desarrollen lo mejor posible.

Por último, a modo de valoración de la aportación pedagógica de Kubik, este trabajo resalta la cimentación de la obra teatral en el juego haciéndose imprescindible su comprensión a partir de dos perspectivas:

1. El juego simbólico en relación con el desarrollo infantil siguiendo la concepción y la perspectiva de Piaget sobre la formación del símbolo en el niño (1990) y la aplicación a las artes y a la educación de los profesores e investigadores Abad y Ruiz de Velasco (2011).

2. El juego dramático (o dramatización) como herramienta pedagógica (Cañas, 2008; Cervera, 1996; Motos, 1996; Navarro, 2007; Tejerina, 1994) у como iniciación a la educación artística basándose en la vivencia y la experimentación propuesta por Barret (1991).

\subsection{Del juego simbólico al juego dramático}

Si el juego es la manera normal que tiene el niño de vivir, constituye en tal caso el mejor modo de enfocar cualquier forma de educación (Slade, 1978: 54).

Piaget (1990) argumenta que el juego tiende a construir una amplia red de dispositivos que permiten al niño la asimilación de toda la realidad, incorporándola para revivirla, entenderla o compensarla. Gracias al juego, los niños y las niñas manipulan la realidad; la asimilan, reproducen y aprenden a entenderla utilizando 
el método científico de ensayo-error, al fin y al cabo, contribuyendo a su proceso de maduración y desarrollo físico, psíquico y emocional. Profundizando en esta teoría hay una clara interconexión entre la expresión dramática (la dramatización) y el juego, ya que, fundamentalmente, esta se va a nutrir de tres pilares esenciales del propio juego: los juegos de percepción, los motores-expresivos y los de imitación-representación (Cañas, 1994). A partir de esta observación se posibilita el encuentro y la comprensión del juego, el desarrollo infantil y el arte dramático.

\subsubsection{El juego simbólico}

El desarrollo de la función simbólica es el elemento fundamental de la actividad cognitiva en la edad preescolar, preoperacional o prelógica ( $0-6$ años). Es gracias a esta función cuando las niñas y los niños pasan de la inteligencia práctica sensorio motora a la inteligencia conceptual y esto lo hacen gracias al juego (sobre todo simbólico). La inteligencia, afectividad, competencia lingüística, conocimiento y desarrollo social aparecen integrados y mutuamente reforzados por esta forma de juego considerado como una plataforma inigualable para el aprendizaje (Tejerina, 1994).

Vigotsky señala el desarrollo a través de la actividad lúdica y añade que el juego estimula el desarrollo de las funciones psicológicas superiores y está en el origen de la imaginación y la creatividad (en Tejerina, 1994). A su vez Bruner argumenta que al no ser real y no tener peligro el juego es una zona privilegiada de entrenamiento para la vida (en Tejerina, 1994). Además de para explorar y disfrutar el juego da cabida a necesidades insatisfechas, dándole oportunidad a la criatura de resolver problemas de una manera segura.

El juego simbólico se relaciona con el juego dramático de manera directa y clara: en el juego infantil de imaginación, específico y espontáneo (el juego simbólico), los niños y las niñas se apropian de la realidad y la nombran en un lenguaje que corresponde a su naturaleza esencialmente fijada en la acción (Tejerina, 1994). En esta acción el juego se transforma en un instrumento simbólico de gestos o de signos verbales que finalmente se constituye como lenguaje dramático.

Hay un como si que se hace acción (drama = acción) en la realidad jugada apoyado en un lenguaje corporal y, sobre todo, verbal. Además, el juego ayuda a liberar la agresividad y canalizar conflictos mediante las combinaciones piagetianas: puede realizar lo prohibido, superar situaciones desagradables, aceptar situaciones que le provocan miedo y anticipar de alguna manera los resultados de la acción (Abad y Ruiz de Velasco, 2011).

En referencia a los tipos de juego simbólico Licona (2000) destaca los siguientes niveles: el juego de "hacer como si", el juego de roles y el juego de representación, tres formas de juego que aparecen tanto en el desarrollo infantil como en el arte dramático. 


\subsubsection{Juego dramático}

En el mundo anglosajón recibe el nombre de drama, creative drama, improvised drama; en el área francófona le llaman jeu dramatique o expression dramatique, y en español se han generalizado las formas juego dramático y, sobre todo, dramatización. Estos conceptos se refieren a aquella actividad que utiliza la herramienta teatral en una práctica lúdica orientada hacia sí misma y sin proyección exterior. Un conjunto de prácticas al servicio de la expresión creadora del individuo y al desarrollo integral de su personalidad. Tiene su sentido último en una concepción no elitista del teatro y en la convicción de que el gran artista se hace con especiales cualidades y mucho trabajo, pero que el germen del arte y la necesidad de manifestación estética está en cada ser humano, y es saludable y recomendable desarrollarlo (Tejerina, 1994).

Jenger añade que el juego dramático es un juego de grupo descubierto gracias al adulto que tiene también un lugar en él y que está sometido a reglas siendo la más importante la de aceptar la participación de los otros y la cooperación de los elementos que constituyen el grupo de jugadores (en Cañas, 1994).

Algunas de las prácticas que engloba el juego dramático o la dramatización son las siguientes: imitaciones, improvisaciones, juegos de roles, dramatizaciones de cuentos, historias inventadas por el grupo, propuestas del animador, adaptaciones de textos de autor, etc. Se trabajan todos los tipos de expresiones: lingüística, corporal, plástica y rítmico-musical, y se pueden utilizar diferentes tipos de técnicas: elaboración de historias, composición de canciones y ritmos, confección de disfraces, construcción de máscaras, objetos escenográficos, pintura de decorados, etc. (Tejerina, 1994).

El juego dramático vive junto a otro concepto que en la práctica viene a ser su sustituto semántica y socialmente: dramatización. Cervera (1996) nos dice que este es un proceso mental y también el resultado de este proceso, su representación.

\subsection{Objetivos de la investigación}

Tal y como se ha explicitado el principal objetivo de esta investigación es conocer los recursos pedagógicos y artísticos que utiliza la Compañía de Teatro Paraíso en la obra Kubik y evidenciar si aportan herramientas pedagógicas válidas para contribuir al desarrollo cognitivo, social y emocional de las niñas y niños de 1 a 3 años. En concreto los objetivos que persigue esta investigación son:

1. Describir las aportaciones pedagógico-artísticas innovadoras basadas en el juego simbólico y dramático de la obra Kubik.

2. Describir cómo se utilizan los recursos escenográficos para generar una comunicación interactiva con las niñas y los niños.

3. Describir cómo se utilizan el movimiento y la manipulación de los objetos para provocar el juego dramático. 


\section{MÉTODO}

\subsection{Diseño y procedimiento}

La investigación se ha realizado en dos fases, una que ocurre durante la celebración de las "II Jornadas de Arte y Pequeña Infancia" en la Escuela Universitaria de Magisterio de Vitoria-Gasteiz, momento en que se asiste al visionado de la obra, donde se realizan observaciones y se toman notas de campo; y un segundo momento, en el que se recogen las impresiones de las personas que habían participado de esta iniciativa, en la que se realizan grupos de discusión y entrevistas a las personas de la compañía.

Se recogieron las observaciones e impresiones del equipo investigador en torno a lo que ocurrió en dicho espacio escénico, para lo que se realizaron grabaciones de vídeo y audio y se tomaron notas de campo. Y con posterioridad a la representación se recogieron las impresiones de las y los estudiantes a través de cuatro grupos de discusión (ver Tabla 1). Asimismo, se realizaron un par de entrevistas a las personas responsables de la compañía para conocer su interés para gestar la obra. En este artículo se ponen en discusión las impresiones recogidas por el grupo de estudiantes y las impresiones recogidas por parte de las personas de la compañía, que son trianguladas con las impresiones recogidas en las observaciones por el grupo investigador.

TABLA 1

Instrumentos utilizados para recoger la información

\begin{tabular}{|c|c|c|c|}
\hline OBJETIVO & CUÁNDO & ESTRATEGIAS & INSTRUMENTO \\
\hline $\begin{array}{l}\text { Recoger información } \\
\text { sobre las reacciones de } \\
\text { las niñas y los niños } \\
\text { y sobre las actitudes } \\
\text { e impresiones que se } \\
\text { recogen del alumnado } \\
\text { universitario conforme se } \\
\text { va desarrollando la obra }\end{array}$ & $\begin{array}{l}\text { Durante la } \\
\text { representación } \\
\text { teatral en las "II } \\
\text { Jornadas de Arte y } \\
\text { pequeña infancia" }\end{array}$ & Observación & $\begin{array}{l}\text { Notas de campo } \\
\text { del equipo } \\
\text { investigador, } \\
\text { grabaciones de } \\
\text { vídeo y de audio }\end{array}$ \\
\hline $\begin{array}{l}\text { Recoger las impresiones } \\
\text { de las personas que han } \\
\text { participado en la obra }\end{array}$ & $\begin{array}{l}\text { Tras la } \\
\text { representación } \\
\text { teatral }\end{array}$ & $\begin{array}{l}\text { - Grupos de } \\
\text { discusión con } \\
\text { el alumnado } \\
\text { universitario y } \\
\text { con docentes de } \\
\text { infantil } \\
\text { - Entrevistas en } \\
\text { profundidad a } \\
\text { las personas de } \\
\text { la Compañía }\end{array}$ & $\begin{array}{l}\text { - Guion de grupos } \\
\text { de discusión y } \\
\text { de entrevistas. } \\
\text { - Grabaciones } \\
\text { en audio y sus } \\
\text { transcripciones }\end{array}$ \\
\hline
\end{tabular}


La investigación se ha llevado a cabo en el mismo lugar donde se ha producido el hecho educativo y con las personas que se han investigado. La función quién investiga ha sido la de sumergirse en el contexto y establecer un diálogo con el mismo y desde el mismo (Valles, 2003). Se negocia el acceso al campo con las dos escuelas infantiles participantes y con la propia compañía de teatro. Para recoger la información se utilizan como estrategias la entrevista (Flick, 2004) y el grupo de discusión siguiendo los postulados de Callejo (2001), Limón y Crespo (2002) y Krueger (1991).

\subsection{Participantes}

En esta investigación ha participado el alumnado del Primer Curso del Grado de Educación Infantil durante el curso 2011-2012 de la Escuela de Magisterio de Vitoria-Gasteiz, como espectadores de la obra teatral acuden 60 personas, de las que tan solo 33 toman parte en los cuatro grupos de discusión. Asisten a ver la obra unos 15 niños y niñas de 2 años en cada representación y cuatro educadoras de dos centros educativos concertados de Vitoria-Gasteiz, así como el equipo investigador HEZIKERT, la directora pedagógica y una actriz de la Compañía Teatro Paraíso de Vitoria-Gasteiz.

\subsection{Codificación de las respuestas en función de los instrumentos}

Tal y como se ha presentado en la Tabla 1, para la recogida de datos en la investigación se han utilizado diferentes instrumentos, para facilitar la identificación de los documentos de los que ha sido extraída la información se destacan los siguientes códigos: para las notas de campo recogidas por el equipo investigador (NC1: Notas de Campo investigador 1); las grabaciones audiovisuales de la obra teatral y sus transcripciones (Obs1); las entrevistas cualitativas realizadas a los componentes de la compañía teatral (EAct1 y EAct2); y los grupos de discusión del alumnado universitario de la Escuela de Magisterio que asistió a la primera representación de Kubik (GD1 a GD4).

\subsection{Procedimiento en el análisis de datos}

El procedimiento de análisis ha sido inductivo, dinámico y sistemático y ha requerido reconocer, clasificar, comparar e interpretar el significado de las opiniones recogidas. Gracias a este proceso se han podido extraer las ideas principales de los fenómenos observados (categorías) y los fenómenos que subyacen a esos conceptos (subcategorías) (Rodríguez, Gil y García, 1996; Coffey y Atkinson, 2003). Y estas categorías han sido organizadas y jerarquizadas en función de un sistema categorial (ver Tabla 2), que además de servir de herramienta para el análisis organiza el informe interpretativo a la hora de ordenar la presentación de los resultados.

Los datos recogidos mediante los diferentes instrumentos han sido digitalizados y organizados tras acordar un único sistema de categorías a través del 
programa NVivo8. La triangulación es intersubjetiva pues procede de diferentes informantes que informan sobre un mismo hecho (Lincoln y Guba, 1985) y procede de diferentes fuentes de información. La información se organiza en nodos ramificados y han sacado los sumarios de cada una de las categorías, para poder reconstruir los correspondientes informes interpretativos (Coffey y Atkinson, 2003).

TABLA 2

Sistema categorial

\begin{tabular}{|c|c|c|}
\hline DIMENSIONES & CATEGORÍAS & SUBCATEGORÍAS \\
\hline \multirow{3}{*}{$\begin{array}{l}\text { 3.1. Valor pedagógico } \\
\text { de la obra: } \\
\text { adecuación a la } \\
\text { primera infancia }\end{array}$} & $\begin{array}{l}\text { 3.1.1. Desarrollo de capacidades } \\
\text { artísticas }\end{array}$ & \\
\hline & \multirow{2}{*}{$\begin{array}{l}\text { 3.1.2. Comunicación cercana } \\
\text { (interacción) }\end{array}$} & 3.1.2.1. Escucha activa \\
\hline & & $\begin{array}{c}\begin{array}{c}\text { 3.1.2.2. Atención a la } \\
\text { interacción }\end{array} \\
\end{array}$ \\
\hline \multirow{2}{*}{$\begin{array}{l}\text { 3.2. Herramientas } \\
\text { utilizadas }\end{array}$} & $\begin{array}{l}\text { 3.2.1. Preparación del espacio } \\
\text { (acogida, desarrollo, despedida) }\end{array}$ & \\
\hline & 3.2.2. Recursos escenográficos & \\
\hline \multirow{2}{*}{$\begin{array}{l}\text { 3.3. El movimiento y } \\
\text { el juego dramático }\end{array}$} & $\begin{array}{l}\text { 3.3.1. Provocar el movimiento a través } \\
\text { de los objetos }\end{array}$ & \\
\hline & $\begin{array}{l}\text { 3.3.2. El juego simbólico: interactuar a } \\
\text { través del juego y el movimiento }\end{array}$ & \\
\hline
\end{tabular}

\section{RESUlTAdos}

En los resultados de esta investigación se evidencia el proceso de la obra teatral Kubik respetando las tres fases que propone la Compañía Teatro Paraíso: la sesión formativa previa con el profesorado; diferentes representaciones de la obra; y la valoración posterior del público adulto, profesorado y actores. A continuación se recogen y analizan algunas de las voces más representativas que relatan el proceso pedagógico vivido a través del juego simbólico y dramático propuesto en Kubik en tres categorías: el valor pedagógico y la adecuación a la primera infancia; las herramientas utilizadas; y el juego simbólico (interactuar a través del juego y el movimiento).

La primera categoría analiza el valor pedagógico de la obra en sí misma y la conexión con el modo de expresar, comunicar y estar en el mundo de los niños y niñas en la etapa a la que está dirigida: de 1 a 3 años. La segunda categoría recoge la situación espacio-temporal, la escenografía y los materiales utilizados: por un lado, se valora el acondicionamiento del escenario para este tipo de público; y, por otro, se da cuenta de los medios de que disponen, la luz y los colores, los objetos, las imágenes y los actores. En la última y tercera categoría se describen el movimiento y la manipulación de los recursos citados en el anterior apartado evidenciando la hipótesis principal de esta investigación de que Kubik se basa en 
la acción, la interacción y el juego compartiendo las inquietudes y experiencias pedagógicas y artísticas del grupo Teatro Paraíso.

\subsection{El valor pedagógico y la adecuación a la primera infancia}

La mayoría de textos referentes al teatro en la educación sostiene que el juego dramático en el aula contribuye al desarrollo del alumnado tanto en el plano personal como en el plano socio-relacional, los cuales se desarrollan paralelamente como veremos en los siguientes apartados.

\subsubsection{Desarrollo de las capacidades artísticas}

La dramatización contribuye a adquirir las competencias básicas desde todas las materias y desde la perspectiva del juego. Según la directora pedagógica del grupo Teatro Paraíso el arte puede ayudar en el desarrollo y la educación integral de los alumnos y alumnas de educación infantil y, para ello, las maestras y maestros pueden hacer uso de los conocimientos artísticos que tengan y llevarlos a clase.

La idea es aprovechar las capacidades artísticas de las personas que tenemos en las escuelas. Hay gente que hace cosas de danza, que hace cosas de música, que le gusta cantar, pintar. Tenemos unas capacidades artísticas que queremos poner en juego en relación a lo que vayamos a hacer después (EAct1).

De esta manera, la dramatización (y el arte dramático) hace su aportación al desarrollo de la creatividad, el área artística, las habilidades expresivas y comunicativas y las habilidades sociales, entre otras. Se hace una propuesta de vivir el teatro a través de las emociones y descubrir nuevos mundos de la mano de la imaginación. Como se observa en las voces recogidas de los grupos de discusión con el alumnado universitario que acudió como público a la representación de la obra Kubik, estas personas observan que también se trabajan los sentimientos y la imaginación en esta obra.

A1: Para mí lo que cada uno pueda sentir en su interior o lo que personalmente siente como niño. Por ejemplo, lo que podría ser entre los adultos, para mí podría ser un sentimiento y para otro, que para los niños todo es más nuevo y no sé cómo decirlo, dignidad o así [...] eso para mí son también sentimientos internos, hacer pensar, o tu paranoia así en la cabeza.

Inv9: Imaginación...

A1: Sí pero la de cada una o... (GD2).

\subsubsection{Comunicación cercana}

En lo que respecta al mundo infantil y a su particular forma de expresarse y comunicarse aparecen dos puntos de vista en las voces recogidas: el público joven (el alumnado universitario) ha entendido que los actores pretenden actuar como 
si fueran niños y niñas, imitar las maneras infantiles; el actor y la actriz en cambio explican su esfuerzo por establecer una comunicación cercana con el público infantil para lo cual debe hacerse una escucha activa y durante el proceso ha de haber una interacción en todo momento, para conocer qué necesitan, qué les gusta y qué temen los niños y las niñas participantes.

A2: ¿Cómo es, expresión corporal o no? Pues igual enfadado o, “ies mío!», no sé, como niños. Por eso yo pensaba que estaban haciendo un papel de niño y les pregunté, ¿pero vosotros qué, estabais haciendo el papel de niños y niñas en la escuela? Y que no, que eran adultos y entonces yo ahí no lo entendí bien. O sea en una clase hablando como los niños y las niñas y todo no: "es mi casa, es..." no sé. Por eso pensaba que estaban haciendo el papel de niños, pero que no, eran adultos (GD2).

La capacidad de adaptarse al lenguaje de niñas y niños que muestran las personas de la Compañía no son captadas por el alumnado universitario, sin embargo, sí comprenden que las personas de la compañía deben estar abiertas a las necesidades de grupo por medio de la escucha activa. Pero todas estas cosas hay que experimentar mucho más porque para que una cosa digas que no necesitas ver qué pasa, porque cada grupo de niños es diferente (EAct1).

¿Qué hicimos? Un juego de construcciones, con el que juegan ellos de la misma manera que los actores juegan como adultos que son, pero, inspirados con el juego que hacen los niños y las niñas en esas edades (EAct 2).

Aunque al final, estos alumnos/as se han dado cuenta de la atención que prestan el actor y la actriz a la respuesta de las niñas y los niños durante la representación y a la interacción en cada experiencia vivida y compartida. Esta interacción se ve refleja en la escucha, la mirada, los gestos, las posturas y el movimiento, en general, las reacciones de los pequeños/as.

A3: De palabras hubo poco pero después, yo creo que los del teatro estaban atentos, porque cómo reaccionaban los niños y las niñas y a veces, también, no sé, hacían como una especie de juego entre los dos (GD1).

El alumnado es consciente de que existe una interacción buscada, intencional, que está provocada por la compañía

A4: Yo creo que sí, bueno no sabemos cómo tenían pensado hacerlo. Pero igual, ¡no sé!, tenían que hacer una cosa y la atención de los niños y las niñas [...] pues no se han sorprendido o... y entonces igual han pensado encaminarlo de otra manera (GD3).

\subsection{Las herramientas utilizadas}

Para lograr la cercanía al público que pretende Kubik, además de estar muy atentos a las reacciones del público en cada momento, como hemos expresado 
anteriormente, preparan con mucho mimo el espacio y el tiempo antes de la representación, durante el proceso y al finalizar.

\subsubsection{La preparación del espacio}

Cuidan de que las niñas y los niños estén cómodamente sentados y que sientan la cercanía con los actores, se preocupan de que no se asusten al apagarse la luz y de que no sientan ni frío ni calor en exceso.

En cuanto al tiempo lo dividen en tres partes: acogida, obra y despedida. Antes de que comience la obra, cuando los pequeños entran en la sala se hace una acogida por parte de los actores con el objetivo de que los conozcan, no se extrañen y se sientan cómodos en esa nueva situación. Al terminar la representación los actores se acercan a los niños y las niñas y les enseñan las imágenes que han estado manipulando en la obra para que ellos y ellas también puedan participar. Los actores participantes piensan en un espacio para jugar a la hora de planear la escenografía, un lugar para disfrutar, para vivir la experiencia teatral, donde el público se sienta a gusto a pesar de que este sea desconocido y nuevo.

La segunda parte es la obra, es el espectáculo con niñas y niños de 1 a 3 años que es con quien se va a hacer la obra. Es especial por el espacio que es pequeño, ya que se necesitan espacios pequeños y otras maneras de acogida (EAct1).

\subsubsection{Los recursos escenográficos}

Los recursos utilizados en esta obra son las figuras geométricas grandes, los cubos que dan nombre a la obra teatral, hechos de cartón y pintados de blanco, con los que además de jugar y crear situaciones diferentes construyen escenografías y diversos ambientes. Más tarde aparecen unas imágenes proyectadas tanto en las figuras geométricas, como en las paredes, en el techo, en el suelo o en los cuerpos vestidos de negro de los actores.

Utilizan pequeños proyectores de imágenes que llevan en la mano y de allí salen animales, ventanas o puertas, o un tren en movimiento, incluso el mar ofreciendo diferentes formas de ver las cosas, mostrando la polisemia de los símbolos. La sala está a oscuras y la escenografía y los actores tienen colores básicos (blanco los objetos y negro los actores). De esta manera los actores pueden proyectar libremente las imágenes donde quieran, y darles vida y movimiento al manipularlas y moverlas por el espacio.

Luego vienen las imágenes. Necesitábamos neutralidad para proyectar sobre ellos mismos. Para que lo importante no fuera esa presencia estética sino el propio juego y las imágenes. Necesitábamos que fuera liso, si metíamos color las imágenes no funcionaban. Por otro se dejó en blanco y negro en esa simplicidad para que cuando se proyectara esa imagen tuviera una inclusión, presencia mayor (EAct1). 
No son solo las imágenes, todo el atrezzo es importante, la vestimenta es otro de los recursos escénicos, el juego de colores dentro del escenario, que lleva a establecer símbolos similares a los que se establecen en el juego simbólico.

La vestimenta, el vestuario es una opción, es una apuesta, [...] se decidió que la ropa fuera negra, y esto responde a un porqué [...] para que las imágenes se mezclen con la propia vida. La idea es que el punto de luz está en las manos, en los pies, en el rostro y en las construcciones blancas, que es donde se focaliza la luz. Todo lo que lleve dibujo hace que no se pueda proyectar o que pierda definición lo que se proyecta, se necesitaba neutralidad para jugar con las imágenes. Por ello, el blanco y el negro, para resaltar la imagen, para darle mayor presencia (EAct2).

Las imágenes forman parte de ese relato simbólico que pretende apropiarse de la realidad, superar los miedos y las situaciones desconocidos, desde aquellos símbolos más sencillos y conocidos.

Hay una grabación del movimiento, por ello van saliendo de uno en uno los animales, el perro, la vaca, después el niño está en el mar. Queríamos no poner el valor en cuál es la imagen que está bien hecha, para que esto pueda hacerse de muchas formas (EAct2).

\subsection{El juego simbólico: interactuar con el juego dramático y el movimiento}

En Kubik, según los objetivos de sus creadores, los cubos y las imágenes invitan a jugar, a interactuar con ellas, es una forma de 'provocar' al público infantil. Es por esto que se puede afirmar que la propuesta artístico-pedagógica se basa en la (inter)acción, es decir, en el motor del juego (y el teatro) que son la base de la comunicación.

En la obra de Kubik, se quiere pasar de la imagen plana a las tres dimensiones, por ello, se llevará un cubo blanco (como los de la obra), que se abre, y de él salen imágenes, [...], nuestra preocupación por que las imágenes no solo sean para verlas, sino para que se pueda jugar con ellas, que se puedan tocar (EAct1).

A5: Intentaban coger los animales cuando salían del suelo, y se emocionaban mucho. Como salían del suelo, pues también interactuaban más los niños con lo que estaban viendo (GD4).

Llevan a cabo juegos de construcción de escenografías con los cubos y manipulan las imágenes rompiendo con la idea de imagen para ser observada pasivamente y promoviendo el movimiento y la experimentación, porque las imágenes en Kubik están en movimiento, los actores interactúan con ellas y también las mueven de un lugar a otro gracias a los pequeños proyectores que manipulan.

En Kubik la manipulación tiene importancia, no es la perfección sino que se juega con las tecnologías, se juega y se encuentra el punto [...] Todo se hace a la vista 

JUEGO, TEATRO Y EDUCACIÓN INFANTIL...

y eso está hecho a propósito y se pone en valor. [...] En el tema de las imágenes queríamos buscar esa parte de liberar las imágenes de las pantallas y hacerlas vivir dentro del espacio del juego (EAct1).

Es el camino artístico para conseguir liberar las imágenes de la pantalla sobre objetos cotidianos. Se basa en los juegos de construcciones. Contraste blanco y negro del arte contemporáneo, minimalista. Hacer una gran búsqueda tecnológica para que los niños vieran que podíamos manipular las imágenes. Presentación de la idea de que las imágenes son algo para manipular, no para ver de forma pasiva (NC2).

La directora pedagógica de Teatro Paraíso subraya la importancia de jugar e interactuar con las imágenes también en el aula, en el día a día, con los álbumes ilustrados, las láminas o las imágenes proyectadas. Y habla de diversas actividades posibles para realizar con formadoras y formadores que lleven a conseguir ese objetivo:

Act1: En el espectáculo de Kubik veíamos que habíamos dejado huellas de imágenes. Que es la forma también de que los niños y las niñas cuando crecen tienden a apropiarse del mundo, a dejar sus propias huellas, dejar imágenes sobre los agujeros... Entonces es una idea también de que podamos dejar huellas, por ejemplo podríamos recortar casas o dibujar casas con personas mayores y dejarlas sobre las paredes como conformando una ciudad. Podríamos poner olas y hacer un gran mar, [...] también podríamos inspirarnos en libros, en imágenes de cuadros, en imágenes de fotografías de los niños, para digamos como final del proceso, dejar imágenes sobre. De esta manera, por ejemplo, se le da, se hace un tema y se hace una composición y luego aquí el final, que es como una escultura de imágenes (NC3).

Dar vida a los objetos y construir desde lo plano es una idea que no se queda en la representación de la obra pues es una de las propuestas que los integrantes del grupo teatral hacen en las Escuelas Infantiles a las maestras que han acudido a la sesión de formación previa. Con eso consiguen subrayar la importancia del proceso sobre el producto acabado:

La idea es hacer un pequeño performance, es decir, [...] una pequeña obrita de dos o tres minutos cuyo tema es la construcción. Es pasar del plano al volumen. Podíamos haber traído las figuras construidas, y ahora las he dejado aquí, pero nos parecía una pena, porque en el trabajo de manipulación con los niños y las niñas esto es un elemento también importante. Y por lo tanto jugar con ellos a la vista y construir con ellos nos parecía que podía ser una cosa importante (NC1).

La idea de la compañía no es otra que tener en cuenta a la infancia como interlocutora de la acción dramática, como protagonista del juego dramático en el momento de elaborarla, tanto en la fase preparatoria, como en cada ocasión de representarla. Y esto lo enfocan sobre todo por medio del placer del juego y de la vivencia teatral.

La obra de teatro crea motivación para continuar jugando (NC3). 
Han querido acercar el teatro y las tecnologías (las imágenes) a las niñas y a los niños y para ello reiteran la importancia del juego y del placer desde la cotidianidad de los infantes, porque es eso precisamente lo que hacen en esta obra con los objetos, experimentar con ellos y manipularlos, jugar con la simbología de los mismos.

Act1: Nos preocupa esto en relación con los niños, porque nos comunicamos con los niños y nos preocupa también en relación al teatro, este arte de trayectoria de siglos, como en un siglo XXI con tanta tecnología. Cómo se relaciona el niño con los objetos y el teatro con las imágenes: a partir de estas dos hipótesis empezamos a trabajar (EAct1).

Act1: Nos parecía importante ofrecerles a los niños cosas que a nosotros nos gustaban mucho que son el teatro, los objetos, queríamos compartir con ellos esta búsqueda y también la idea de que el teatro no es para contemplar sino para jugar, queríamos jugar con los objetos. Esto es lo que encontramos a través del juego con el movimiento y a través del juego con los actores (EAct1).

Jugar con los objetos, con las imágenes supone entrar en un diálogo entre las niñas y niños espectadores y los objetos que son tratados de manera similar a como ellas y ellos los utilizan en sus juegos diarios, en el juego simbólico. El juego simbólico es un recurso pedagógico utilizado para desarrollar el juego dramático, provocando un interés y una interacción mayor.

\section{DisCuSIÓN Y CONCLUSIONES}

El teatro tiene un valor pedagógico debido a que ha tenido siempre una función social educativa (Sánchez, 2007). Este autor también sostiene que la dramatización es tanto una forma de expresión individual, grupal y social como una interacción interpersonal con fines lúdicos y/o pedagógicos. Y añade que el drama constituye un estadio intermedio entre juego y teatro, con el fin de la formación y desarrollo global de la persona. Podemos encontrar la función socializadora teatral, la expresión y la interacción de actores y público, las finalidades lúdico-pedagógicas y la formación global por medio del juego y del teatro en Kubik como hemos observado en los resultados obtenidos.

Motos (1996) propone un gráfico sobre las formas dramáticas y el desarrollo evolutivo del niño, que va desde la espontaneidad a la elaboración técnica por un lado y desde el proceso lúdico al proceso artístico por otro en el que coloca primero el juego simbólico, después el juego dramático, a continuación la representación de papeles y para finalizar el teatro. Tejerina (1994), además, diferencia tres estadios dramáticos en esta evolución infantil: en el primero el juego simbólico, en el segundo el juego dramático o dramatización y en el tercero el teatro.

Al ser Kubik una obra dirigida a un público de 1 a 3 años y siguiendo las clasificaciones anteriores prima la utilización del juego simbólico, el cual consecuentemente está muy presente en esta obra, con la manipulación de los cubos y 
la simbolización de situaciones cotidianas en la vida infantil, o con las imágenes proyectadas de motivos recurrentes y conocidos por este público, todo ello aderezado por la atención y el cuidado de los actores y de su invitación al descubrimiento por medio del juego.

La dramatización está muy ligada al desarrollo de la inteligencia emocional, así como a los aspectos cognitivos, afectivos y psicomotrices del participante (Onieva, 2011: 85). Esto ha quedado recogido en las fases de la experiencia Kubik. La importancia que le dan los artistas a la acogida y a la despedida del público, y a la escucha activa que tienen durante la representación de la obra.

La dramatización como recurso pedagógico posee características muy similares a las que se desarrollan tanto con el constructivismo, el aprendizaje activo o el aprendizaje por descubrimiento (Onieva, 2011: 121). Por lo que se valora altamente Kubik como ejemplo de educación holística basada en el juego, porque tiene en cuenta los conocimientos del público para construir a partir de ahí, utiliza la acción como motor y provoca la interacción comunicativa con las niñas y los niños, e incentiva la autonomía y la curiosidad al proponer diferentes escenografías o situaciones con los cubos y las imágenes.

De esta manera, se ha podido constatar en las evidencias recogidas en este estudio que el arte, el teatro, y en particular la obra dramática Kubik, se presentan como herramientas y medios muy recomendables para el desarrollo evolutivo y la educación global e integral de la primera infancia. Brindan la oportunidad de trabajar todas las competencias en todas las materias escolares y, en el caso de la Educación Infantil, permite hacer una productiva incursión en los ámbitos generales que aparecen en el currículum de esta etapa, a saber, la autonomía y el conocimiento personal; el conocimiento del medio; y la expresión y la comunicación.

Como decía Confucio no es suficiente explicar o mostrar para el aprendizaje, es necesario hacer para interiorizar los conocimientos, al fin y al cabo, experimentar y vivir diversas situaciones para crecer personal y socialmente como propone Barret con "el arte y la ciencia de lo vivido" (1991: 203) privilegiando el proceso sobre el producto final y la experimentación activa e interactiva. De esta forma se podrá llegar a una educación integral y global como mencionábamos al principio de este artículo y dar cabida a la citada polisemia de Barret.

El público infantil interactúa con los personajes, las acciones, los objetos y las imágenes siendo parte de esta experiencia y compartiendo esta vivencia. Aprenden a través del juego actoral y expresan lo que les llega de la obra interactuando dentro de esa situación comunicativa tan cercana.

En resumen, creemos que la obra teatral Kubik hace una importante aportación pedagógica (y artística) y es un recurso innovador para la comunidad educativa por su adecuación al universo infantil y por su apuesta por estructurar la obra basándose en el juego exploratorio natural de la primera infancia:

1. En primer lugar, es una obra dramática dirigida exclusivamente a las criaturas entre 1 y 3 años. Para ello se hace un trabajo previo importante de documentación y elaboración consiguiendo una comunicación apropiada 
con los interlocutores de la obra y conociendo las necesidades e intereses de esa etapa evolutiva. Se cuidan especialmente la situación espaciotemporal, los medios y materiales utilizados (los objetos y las imágenes en movimiento) y la interacción con el público, antes, durante y después de la obra.

2. En segundo lugar, se basa en el juego como medio de expresión personal y de conocimiento social como lo hacen las niñas y los niños de esta edad. Se experimenta, improvisa y descubre a sí mismo, al otro y al mundo. Se manipulan objetos y se comparten imágenes cercanas a la cotidianidad de los espectadores: cubos y figuras geométricas grandes que se pueden encontrar en las aulas de psicomotricidad o imágenes del día a día como animales o elementos de la ciudad o de la naturaleza.

3. En tercer y último lugar, el actor y la actriz comparten una experiencia, la vivencia del teatro, dándoles la oportunidad a las niñas y a los niños de interpretar e interactuar con lo que ven y con lo que viven en esa obra teatral, haciéndoles partícipes de ella en todo momento y proponiéndoles que disfruten con el juego (pedagógico) del teatro. Ello muestra la conexión entre el juego y el drama o el teatro, ya que ambos están basados en la acción, y son propiciadores del valor educativo de esta obra.

La propuesta pedagógico-artística de Kubik no acaba con la representación. Antes de llevar a las niñas y a los niños a la representación de la obra se facilitan al profesorado materiales para ambientar la obra en clase y para ir familiarizando a la gente menuda con lo que se van a encontrar. A continuación, en la sesión preparatoria se les insta a las maestras a darle continuidad en el aula después de la representación primeramente haciendo una valoración de ella con las alumnas y los alumnos y más tarde sacando provecho de lo vivido para continuar entrenándose para la vida a través del juego y del arte dramático que les ha ofrecido esta obra con sus objetos, sus imágenes y su invitación al juego.

Por lo que las niñas y los niños, después de trabajar sobre la obra en clase y de asistir y participar en la representación, continúan recordando retazos de la obra y compartiéndolos con los adultos que tienen alrededor integrando lo aprendido, lo descubierto y lo vivido.

\section{REFERENCIAS BIBLIOGRÁFICAS}

Abad, J. (2006). Escenografías para el juego simbólico. Aula de Infantil, 34, 10-16.

Abad, J. (2009). Iniciativas de Educación Artística a través del Arte Contemporáneo para la Escuela Infantil (3-6 años). Tesis Doctoral. Universidad Complutense de Madrid (Departamento de Didáctica de la Expresión corporal).

Abad, J. y Ruiz de Velasco, A. (2007). Propuesta metodológica para la asignatura "Dramatización" del plan de estudios de Magisterio, Educación Infantil. Pulso: Revista de Educación, 30, 143-170.

Abad, J. y Ruiz de Velasco, A. (2011). El juego simbólico. Barcelona: Graó. 
Barret, G. (1991). Pedagogía de la expresión dramática. Québec: Recherche en expression.

Callejo, J. (2001). El grupo de discusión: introducción a una práctica de investigación. Barcelona: Ariel Practicum.

Cañas, J. (1994). Didáctica de la expresión dramática. Una aproximación a la dinámica teatral en el aula. Barcelona: Octaedro.

Cervera, J. (1996). La dramatización en el aula. Madrid: Bruño.

Coffey, A. y Atkinson, P. (2003). Encontrar sentido a los datos cualitativos. Medellín: Contus.

Cutillas, V. (2006). La enseñanza de la dramatización y el teatro: propuesta didáctica para la enseñanza secundaria. Tesis doctoral. Universitat de Valencia.

Delgado, I. (2011). El juego infantil y su metodología. Madrid: Paraninfo.

Flick, U. (2004). Introducción a la investigación cualitativa. Madrid: Morata.

Giráldez Hayes, A. (2009). Reflexiones en torno al lugar de las artes en la Educación Infantil. Tribuna Abierta. CEE Participación Educativa, 10, 100-109.

Licona, A. L. (2000). La importancia de los recursos materiales en el juego simbólico. PixelBit: Revista de Medios y Educación, 14, 1-6.

Limon, M. R. y Crespo, J. A. (2002). Grupos de debate para mayores. Guía práctica para animadores. Madrid: Narcea.

Lincoln, Y. S. y Guba, E. G. (1985). Naturalistic Inquiry. Newbury Park, C. A.: Sage Publications.

Motos, T. (1996). Dramatización y técnicas dramáticas en la enseñanza y el aprendizaje. En Víctor García Hoz (coord.). Enseñanzas artísticas y técnicas (pp. 113-164). Madrid: Rialp.

Navarro, M. R. y Núñez, L. (2007). Dramatización y educación: aspectos teóricos. Teoría de la Educación, 19, 225-252.

Onieva, J. L. (2011). La dramatización como recurso educativo: estudio de una experiencia entre estudiantes malagueños de un centro escolar concertado y adolescentes puertorriqueños en situación de marginalidad. Tesis doctoral. Universidad de Málaga.

Pérez Parejo, R. (2010). 'Homo ludens' en la dramatización: la dimensión antropológica de la actividad dramática. Escuela Abierta, 13, 55-68.

Piaget, J. (1990). La formación del símbolo en el niño. Buenos Aires: Fondo de Cultura Económica.

Rodríguez, G.; Gil, J. y García, E. (1996). Metodología de la investigación cualitativa. Málaga: Aljibe.

Ruiz de Velasco, A. (2006). Del placer motórico al placer visual. Aula de Infantil. Ámbito $0-6,32$.

Sánchez, M. D. (2007). La dramatización en Educación Primaria como eje del aprendizaje lúdico-creativo. Tesis doctoral. Universidad de Málaga.

Tejerina, I. (1994). Dramatización y teatro infantil. Dimensiones psicopedagógicas y expresivas. Madrid: Siglo Veintiuno.

Vallés, M. S. (2003). Técnicas cualitativas de investigación social. Madrid: Síntesis.

Young, S. y Powers, N. (2008). See theatre: Play theatre. Descargado el día 20 de mayo de 2013. http://starcatchers.org.uk/downloads/research_report.pdf. 